\title{
Fracture Toughness of Short Fiber/Thermoplastic Matrix Composites, Compared on the Basis of Different Test Methods
}

\author{
K. FRIEDRICH, R. WALTER AND J. VOIGT \\ Polymer \& Composites Group \\ Technical University Hamburg-Harburg \\ 2100 Hamburg 90, West Germany \\ M. GROSSO \\ $C E A S T^{\circledR}$ \\ 10146 Torino, Italy
}

\begin{abstract}
A variety of thermoplastic matrices, including Polyethersulfone (PES), Polyoxymethylene (POM), and toughness modified Polyethylenterephthalate (PET), and their short glass fiber reinforced composites have been tested with respect to their impact resistance. Test methods applied, all characterize in some respects the "toughness" of these materials. It turns out, however, that the ranking order of their toughnesses varies quite remarkably, depending on the particular testing procedure. In a fracture mechanics test with compact tension specimens, the fracture toughness of Polyethersulfone, for instance, is very low compared to the other thermoplastics and to their short fiber reinforced versions. This is due to the very sharp notches used in this kind of toughness test, and due to the high notch sensitivity of PES. In a falling dart test with a CEAST ${ }^{\circledR}$ modular falling weight device, and the use of unnotched plates, PES proves to be, on the other hand, much better than all the other competitive materials. The results are discussed with respect to the content of information of the individual tests on the "toughness" profile of the different polymers and composite materials studied.
\end{abstract}

\section{INTRODUCTION}

THE USE OF thermoplastic polymers and their short fiber composites in, e.g., automotive applications often requires a wide range of different mechanical properties. The materials must possess a stiffness which is high enough to

Extended version of a paper presented at the ASC/CCM-Joint Symposium, University of Delaware, September 1987.

68 Journal of Thermoplastic Composite MATERIALS, Vol. 1-January 1988

0892-7057/88/01 0068-26\$4.50/0

(C) 1988 Technomic Publishing Co., Inc. 
guarantee dimensional stability even at temperatures far above room temperature. Also, they must be resistant against any kind of loading conditions which normally may cause crack initiation, crack propagation or even spontaneous fracture. The mechanical property characteristic for the resistance against crack propagation and fracture is the toughness of the material. Different possibilities exist to determine the toughness of polymeric materials. The results of these techniques may differ, however, quite remarkably depending on how the term toughness is understood or defined in these different tests. The toughness can either be related to the critical strength at which a crack starts to propagate in an unstable manner (the typical fracture mechanics approach) or it can be related to the energy necessary to cause crack propagation and fracture of the material. In addition, the individual toughness tests can be different with respect to the stress state (bi-axial or uni-axial loading, two or three dimensional stress conditions) and with respect to the test velocity applied (quasi-static or impact situation).

This study deals with the application of different toughness testing methods to a variety of untoughened and toughened thermoplastic matrices and their short fiber composites. The following objectives should be clarified:

1. The effect of toughening particles and/or short glass fibers on the strength or energy related toughness values of the different thermoplastics tested by three different testing methods

2. Establishing a ranking order between all the different materials with respect to their overall toughness profile

3. Studies of possible correlations between results of the different toughness testing methods

\section{EXPERIMENTAL DETAILS}

\subsection{Materials}

The following polymer matrices were used in this study:

a. A semi-crystalline polyoxymethylene (POM-I) and a particle toughened version of this polymer (POM-IIa)

b. A semi-crystalline, particle toughened polyethylenterephthalate (PET)

c. An amorphous polyethersulfone (PES), which was supposed to be a rather tough material even without any extra toughening component. Plate thicknesses varied between 3 and $4 \mathrm{~mm}$.

In addition short glass fiber composites of these polymer matrices containing different amounts of glass fibers were investigated (Table 1). The fiber orientation patterns in the different composites have in principle the same structure as it has been described in previous papers of the authors [1-3].

\subsection{Testing Methods}

Three types of "toughness" tests were applied to characterize the fracture performance of the various materials. The methods are different with respect to the 
Table 1. List of materials for toughness comparisons.

\begin{tabular}{|c|c|c|c|c|c|}
\hline Material & Code & Nomenclature & $\begin{array}{c}\text { Glass } \\
\text { Fiber w/o }\end{array}$ & $\begin{array}{c}\text { Toughener } \\
\text { w/o }\end{array}$ & Symbol \\
\hline POM-Matrix 1 (Delrin *) & $76-1 a$ & POM-1 & - & - & $\triangle$ \\
\hline$"+25 \%$ GF & $76-3 a$ & 25GF-POM-I & 25 & س- & A \\
\hline POM-Matrix lla & $12-2$ & POM-lla & - & $\cong 40 \mathrm{PU}$ & $\triangle$ \\
\hline$"+25 \%$ GF & $12-6$ & 25GF-POM-lla & 25 & $\cong 40 \mathrm{PU}$ & $\nabla$ \\
\hline PET (Rynite*) & $82-1$ & PET & 一 & $\cong 15$ lon. & $\square$ \\
\hline PET $+30 \%$ GF & $82-5$ & 30 GF-PET & 30 & $\cong 15$ lon. & in \\
\hline PET $+45 \%$ GF & $82-6$ & 45 GF-PET & 45 & $\equiv 15 \mathrm{lon}$. & $\mathbf{B}$ \\
\hline PES (ultrason**) & $E-0$ & PES & 0 & - & 0 \\
\hline PES + $20 \%$ GF & $E-20$ & 20 GF-PES & 20 & - & ( \\
\hline PES $+30 \%$ GF & $E-30$ & 30 GF-PES & 30 & - & 9 \\
\hline
\end{tabular}

* DuPont, USA

* BASF, FRG.

specimen geometry used, the stress state in the material during the test situation, and the loading rate (Table 2):

a. Using an instrumented modular falling weight device (fractoscope AFS-MK3 from CEAST ${ }^{(B)}$, Torino, Italy) rectangular plates $6 \mathrm{~cm} \times 6 \mathrm{~cm}$ in size were impacted by a metallic striker (tip radius $20 \mathrm{~mm}$ ) from the surface. The load maximum and the energy to punch a hole through the plates was measured.

b. An impact pendulum (CEAST ${ }^{\circledR}$, Torino, Italy) (in connection with the same data aquisition unit as in a) and an HP computer, type 9000, series 200/300,

Table 2. Methods for toughness testing.

\begin{tabular}{|c|c|c|c|c|c|}
\hline $\begin{array}{l}\text { Test } \\
\text { Method }\end{array}$ & $\begin{array}{l}\text { Type of } \\
\text { Loading }\end{array}$ & $\begin{array}{l}\text { Stress } \\
\text { State }\end{array}$ & $\begin{array}{l}\text { Measured } \\
\text { Data }\end{array}$ & $\begin{array}{l}\text { Loading } \\
\text { Rate }\end{array}$ & Specimen \\
\hline $\begin{array}{l}\text { Falling } \\
\text { Weight } \\
\text { Test }\end{array}$ & Impact & $\begin{array}{l}\text { three- } \\
\text { dimensional }\end{array}$ & $\begin{array}{l}\text {-Impact } \\
\text { Force and } \\
\text { Energy }\end{array}$ & $\begin{array}{l}\text { variable: } \\
\text { here } \\
6.26 \mathrm{~m} / \mathrm{sec} \\
\max .\end{array}$ & $\begin{array}{l}\text { Plates } \\
\text { and } \\
\text { Structural } \\
\text { Components }\end{array}$ \\
\hline $\begin{array}{l}\text { Izod } \\
\text { Impact } \\
\text { Test }\end{array}$ & $\begin{array}{l}\text {-Impact } \\
\text { Bending } \\
\text {-Notch } \\
\text { Sensitivity }\end{array}$ & $\begin{array}{l}\text { three- } \\
\text { dimensional }\end{array}$ & $\begin{array}{l}\text {-Impact Force } \\
\text { and Energy } \\
\text {-Dynamic } \\
\text { Fracture } \\
\text { Toughness }\end{array}$ & $\begin{array}{l}\text { variable: } \\
\text { here: } 3.46 \mathrm{~m} / \\
\text { sec-max. }\end{array}$ & $\begin{array}{l}\text { Notched } \\
\text { Izod } \\
\text { Samples } \\
\text { (precracked) }\end{array}$ \\
\hline $\begin{array}{l}\text { Fracture } \\
\text { Mechanics } \\
\text { Test }\end{array}$ & $\begin{array}{l}\text {-Static } \\
\text { Tension } \\
\text { - Notch } \\
\text { Sensitivity }\end{array}$ & $\begin{array}{l}\text { two- or } \\
\text { three- } \\
\text { dimensional }\end{array}$ & $\begin{array}{l}\text {-Critical } \\
\text { load } \\
\text {-Static } \\
\text { Fracture } \\
\text { Toughness } \\
\text {-J-Integral }\end{array}$ & $\begin{array}{l}\text { variable: } \\
\text { here: } 1 \mathrm{~mm} / \mathrm{min}\end{array}$ & $\begin{array}{l}\text { Compact } \\
\text { Tension } \\
\text { Specimens } \\
\text { (precracked) }\end{array}$ \\
\hline
\end{tabular}




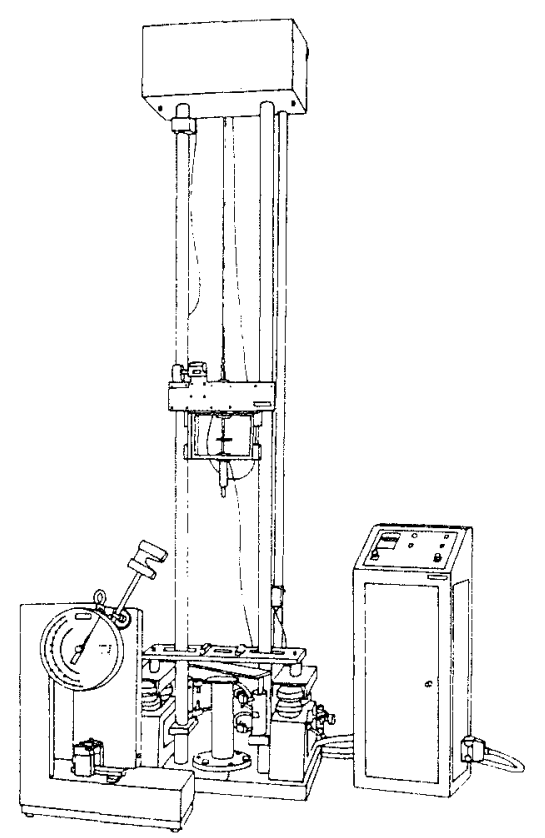

Figure 1. Schematic of the modular falling weight instrument and the CEAST impact pendulum.

were used to impact performance of razor notched IZOD test samples (according to ASTM-D256). Again the load maximum, the energy to peak and the total energy to break the samples were used for further calculations (Figure 1).

c. Fracture mechanics tests were performed with compact tension specimens in order to determine both $K_{c}$-values and $J_{I c}$-values (in cases where stable crack growth could be achieved). The exact testing procedures are described in the ASTM standards E 399 and E 813; a brief description is given in Reference [4].

\section{RESULTS}

\subsection{Modular Falling Weight (MFW) Tests}

The MFW tests resulted in load-displacement-curves of different shapes, depending on the ductility of the polymers and their fiber reinforcement. Figures $2 a$ and $2 b$ indicate the variations in the curves with the addition of toughening particles in POM (Figure 2a) and with fiber content in (under this testing condition) the very ductile PES (Figure $2 b$ ). A comparison between all the different materials on the basis of the load maximum $\left(F_{\max }\right)$ yields the impression that in case of the ductile matrices fibers reduce the load necessary to punch a hole into 


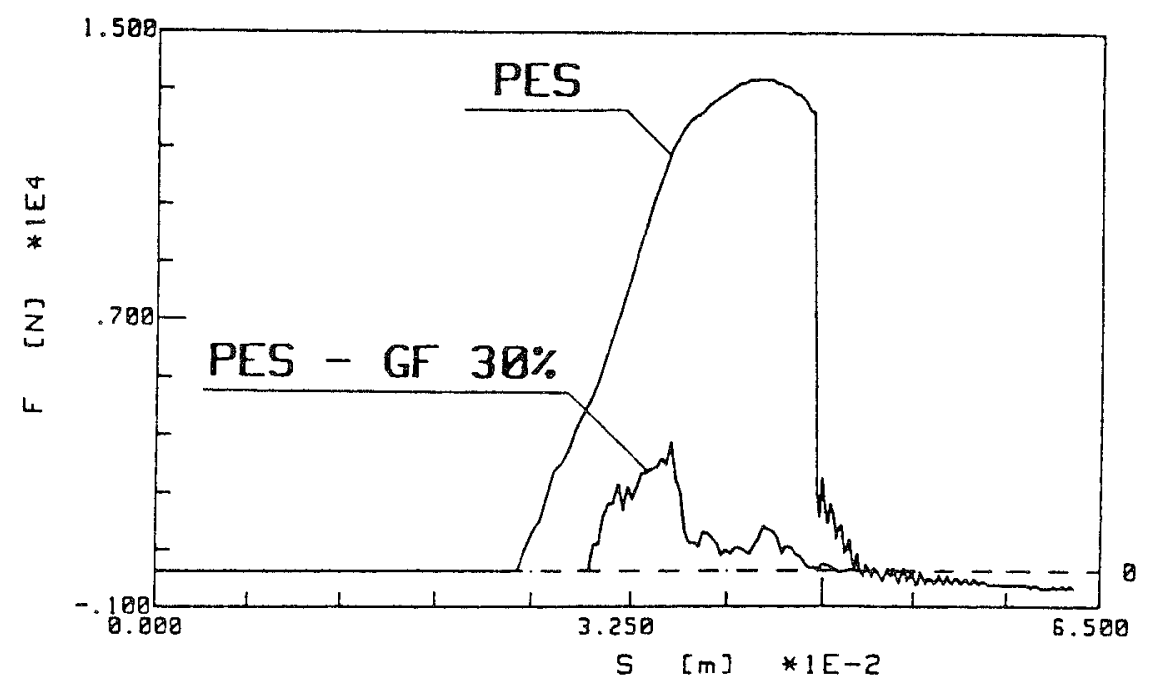

Figure 2a. Load F-displacement s-curves of MFW-tests, performed on unfilled and 30 wt \% GF reinforced PES.

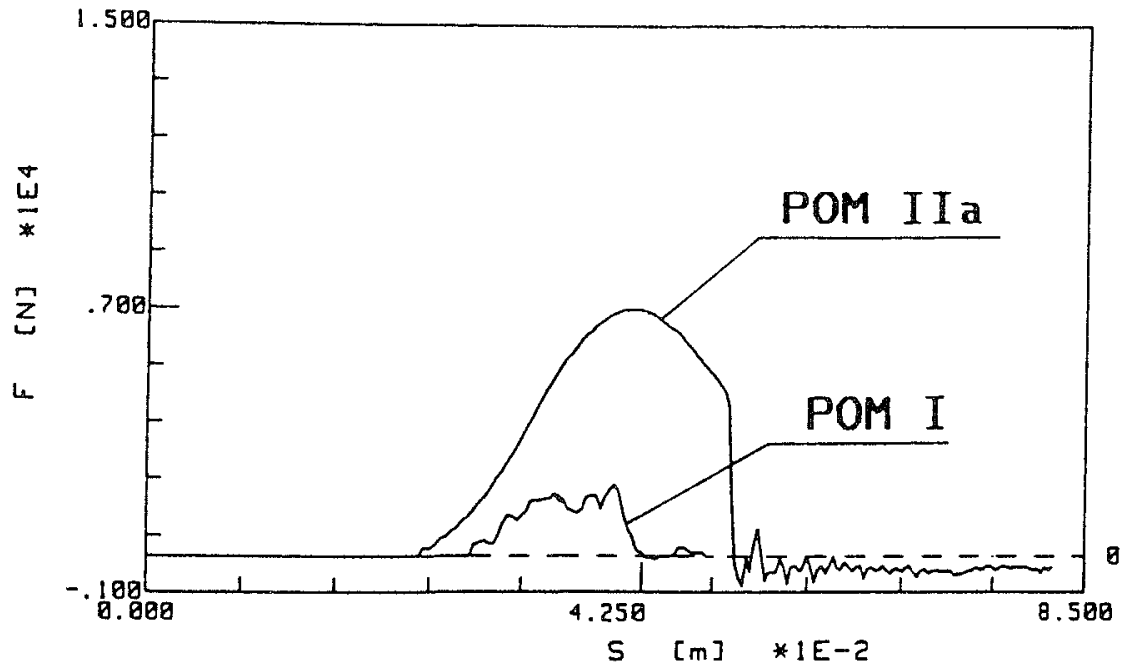

Figure 2b. Load F-displacement s-curves of MFW-tests, performed on unfilled (material $P O M$ I) and 40 wt \% PU-toughened POM (material POM IIa). 


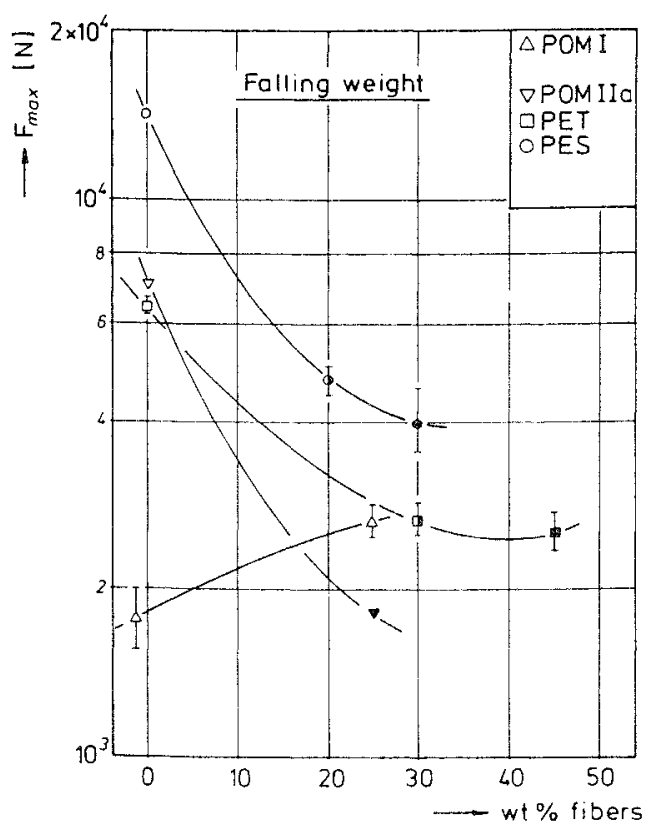

Figure 3. Maximum load, $F_{\max }$, as a function of glass fiber weight fraction for the MFWtests with the different polymer systems.

the plates. The opposite seems to be true for polymers which tend to break in a brittle manner (Figure 3). Both trends are also visible when the energy to peak and total energy to failure are plotted against the weight fraction of fibers in the different polymer matrices (Figures $4 a, b$ ).

To illustrate the different failure modes, Figure 5 shows the broken samples which correspond to the load displacement curves of Figure 2. Round holes with edges reflecting a macroscopically brittle fracture pattern are found for the POM-I matrix and for each of the fiber composites. Sometimes, parts of the punched-out pieces (crosswise broken) kept loosely attached to these holes. POM-II-a, PES and PET exhibited, on the other hand, a conical type of ductile plate deformation which finally ended in a rupture of the tip of this conus (Figure $5 a$, left photo). Higher magnifications of the ruptured surfaces of the unfilled PES and the toughened POM IIa clearly illustrate the very ductile type of failure (Figure $6 \mathrm{a}, \mathrm{b}, \mathrm{c}$ ). In comparison, Figure $6 \mathrm{~d}$ shows the rather brittle fracture surface appearance of the untoughened POM I.

\subsection{Notched Izod Impact (NII) Studies}

Because of the anisotropy of the injection molded short fiber reinforced plates, these tests were carried out with samples in which the notches where either parallel (L-cracks) or perpendicular (T-cracks) to the mold filling direction. In 


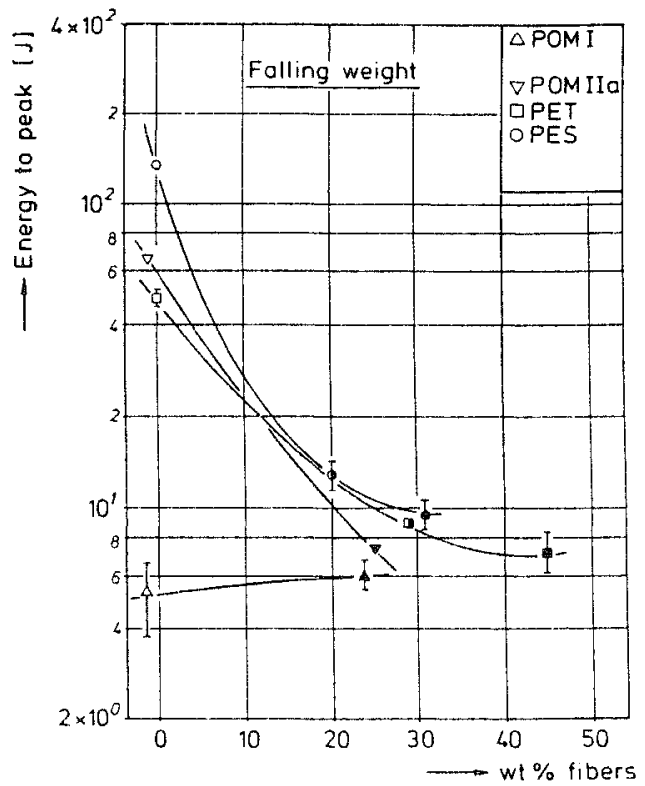

Figure 4a. Energy absorption values measured in the MFW-test: energy to peak.

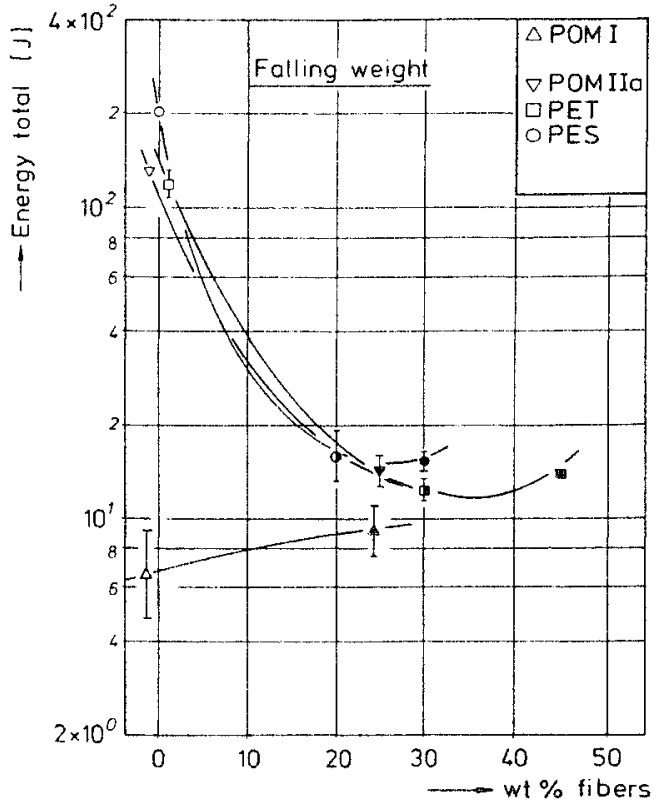

Figure 4b. Energy absorption values measured in the MFW-test: total energy to failure. 


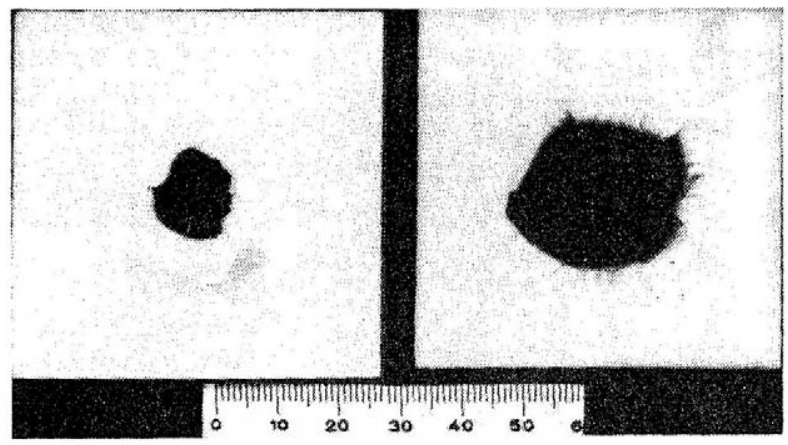

Figure 5a. MFW-test samples, showing different types of failure as a result of materials compositions: POM lla (particle toughened, therefore ductile failure, left) and POM I (brittle fracture, right).

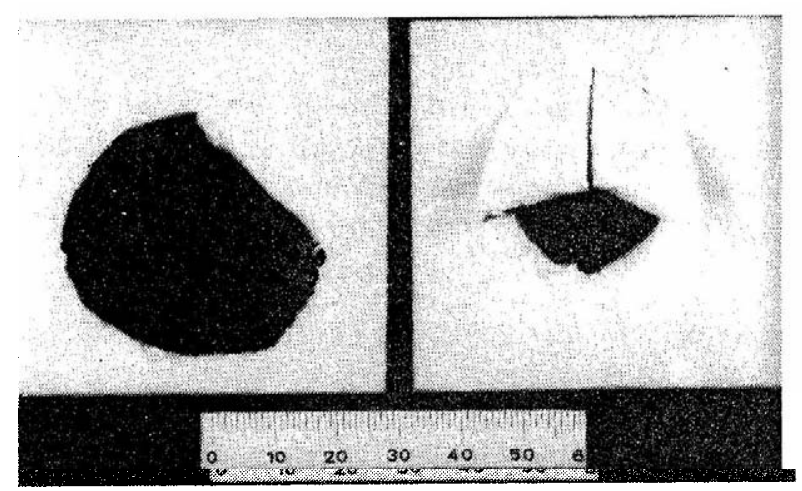

Figure 5b. MFW-test samples, showing different types of failure as a result of materials compositions: $25 \%$ GF.POM I (left) and 25\% GF-POM Ila (right).

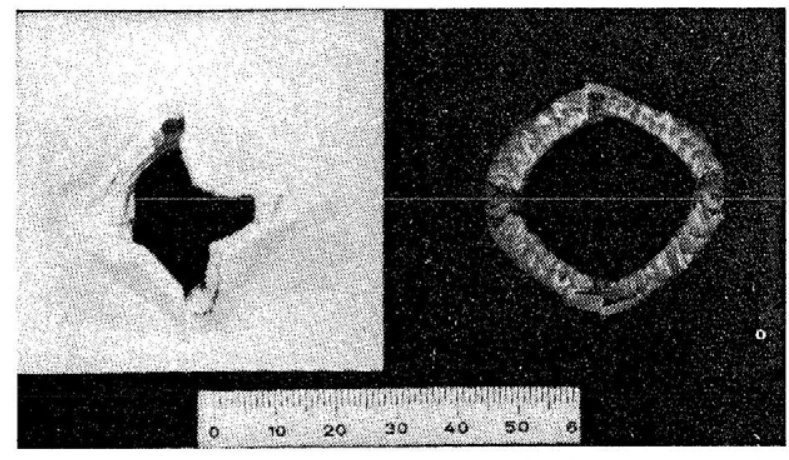

Figure 5c. MFW-test samples, showing different types of failure as a result of materials compositions: $45 \%$ GF-PET (left) and 20\% GF-PES (right). 


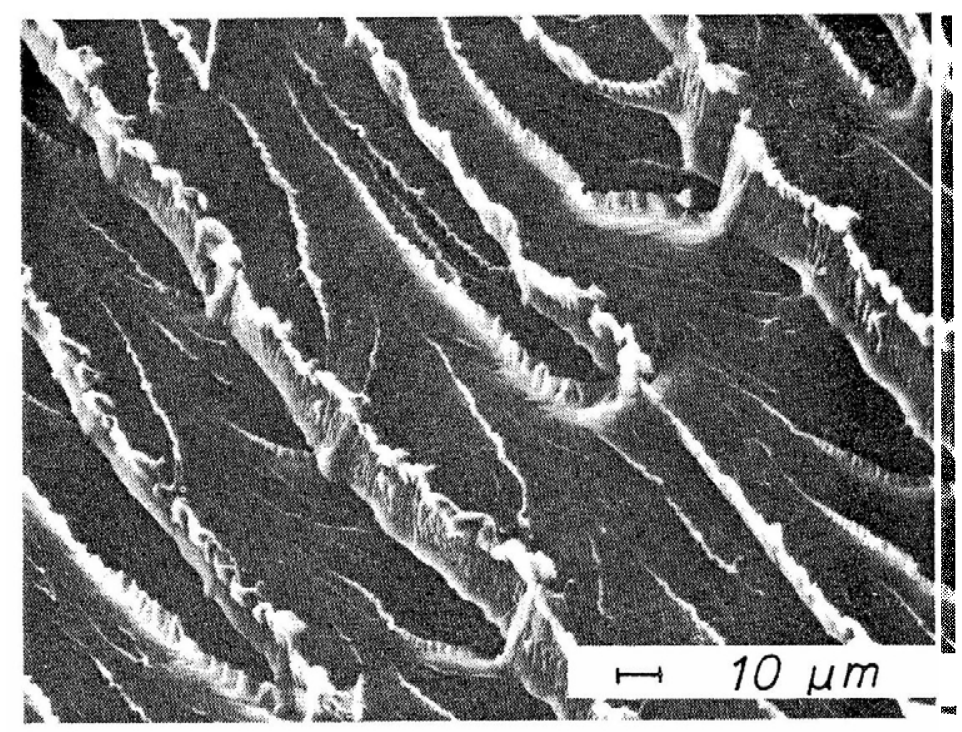

Figure 6a. Higher magnifications of the MFW-samples. Ductile fracture surface of the unfilled PES.

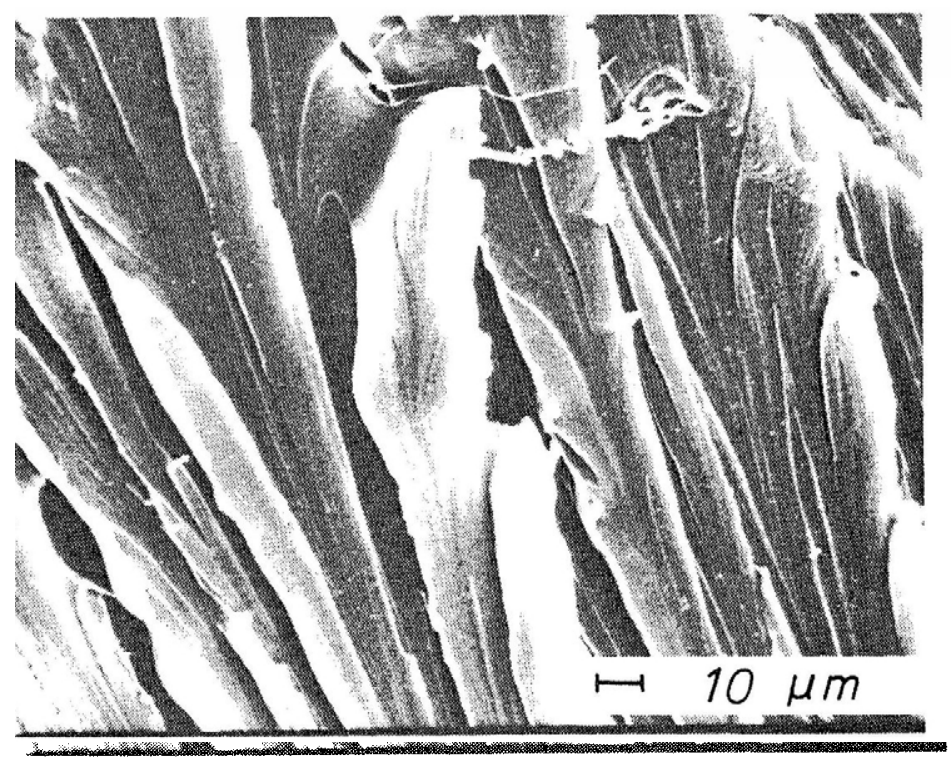

Figure $6 b$. Higher magnifications of the MFW-samples. Ductile fracture surface of the unfilled PES. 


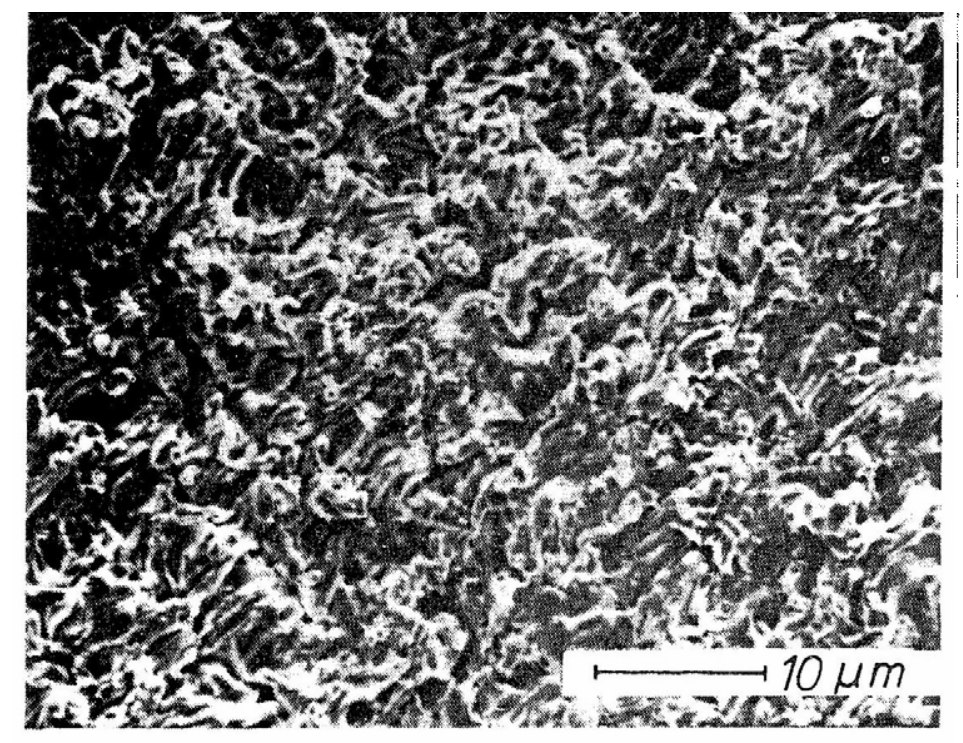

Figure 6c. Higher magnifications of the MFW-samples. Ductile fracture surface of the toughened POM-II.

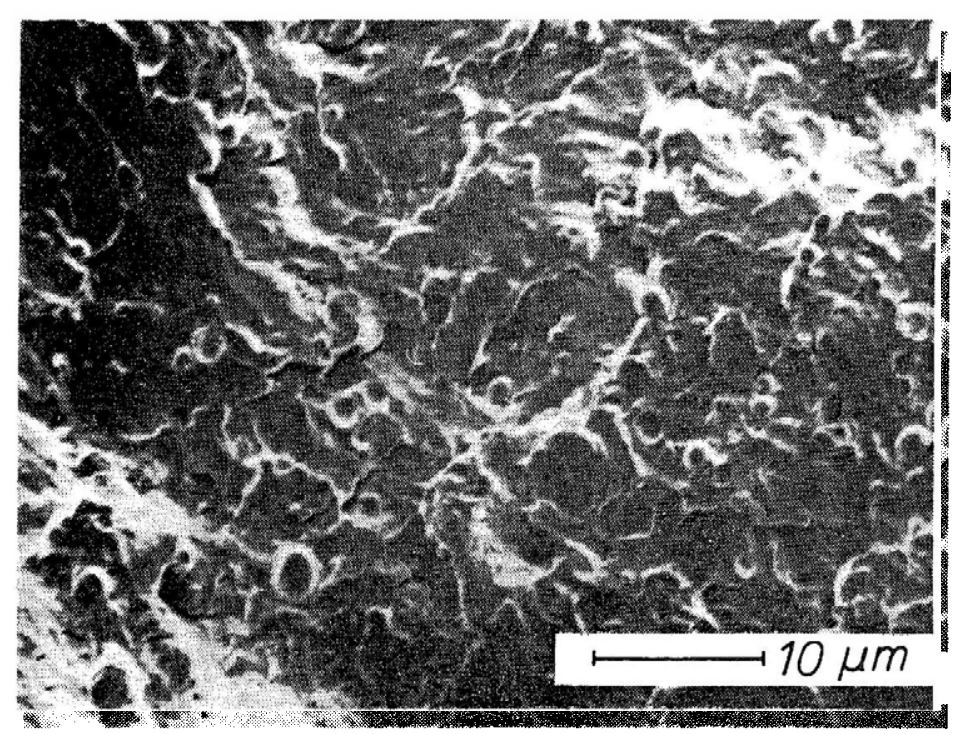

Figure 6d. Higher magnifications of the MFW-samples. Brittle fracture surface of the unfilled POM I. 


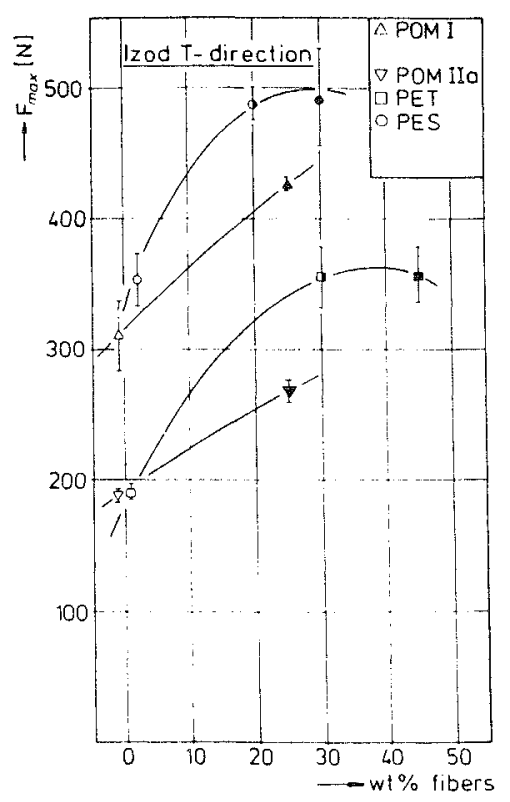

Figure 7a. Maximum load vs. fiber weight fraction for razor notched lzod test samples of the different polymer systems (cracks transverse to the mold filling direction of the injection molded plaques, from which samples were machined, T-direction).

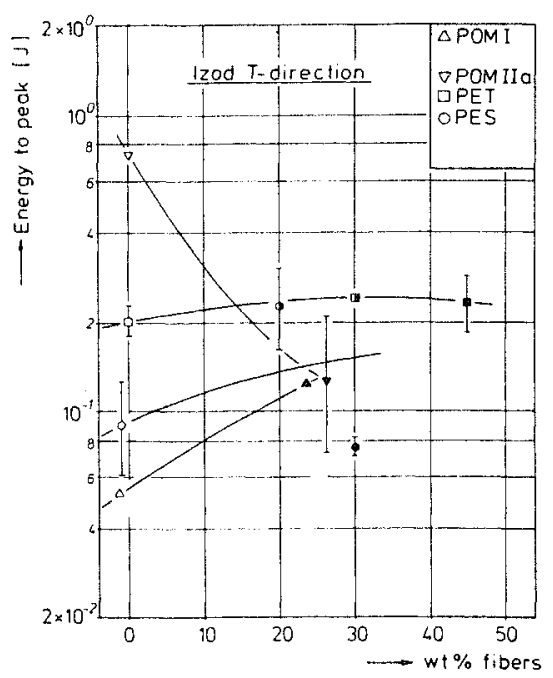

Figure 7b. Energy to peak vs. fiber weight fraction for razor notched lzod test samples of the different polymer systems. 


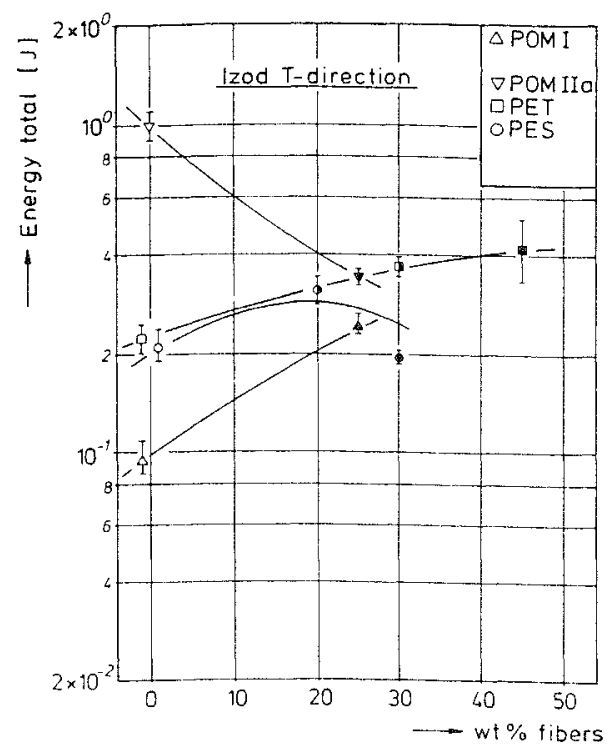

Figure 7c. Total energy to failure vs. fiber weight fraction for razor notched lzod test samples of the different polymer systems.

general, the T-cracks resulted in about 10 to $20 \%$ higher values of both the maximum load and the total energy to break the samples. The data of these T-cracks will be shown here only. Figure 7 illustrates the variation in the measured characteristics with fiber reinforcement in the different polymer matrices. Opposite to the MFW experiments, the Izod studies reflect different trends with respect to the maximum load, energy to peak and the total energy to failure as a function of fiber content.

Some typical appearances of the corresponding fracture surfaces of the fiber filled POM I and POM IIa are shown on Figure 8.

\subsection{Fracture Mechanics (FM) Tests}

The fracture toughness data, $K_{c}$, plotted in Figure 9 versus the fiber weight fraction of the different thermoplastics tested, were calculated from the maxima of the load displacement curves achieved from L- and T-cracked compact tension specimens at a cross-head speed of $1 \mathrm{~mm} / \mathrm{min}$. Although the trend in $K_{\mathrm{c}}$ vs. wt $\%$ fibers is the same as for the maximum load of the NII-test results the relative data level of the 4 material groups is different. The biggest change in the behavior is found for the PES matrix which turns out to have the lowest $K_{c}$ value measured. This is also reflected in the very brittle appearance of the fracture surface of unfilled PES, as illustrated on Figure 10. A comparison to the very ductile nature of the ruptured surfaces in case of the unnotched MFW-test specimens (cf. Figure 


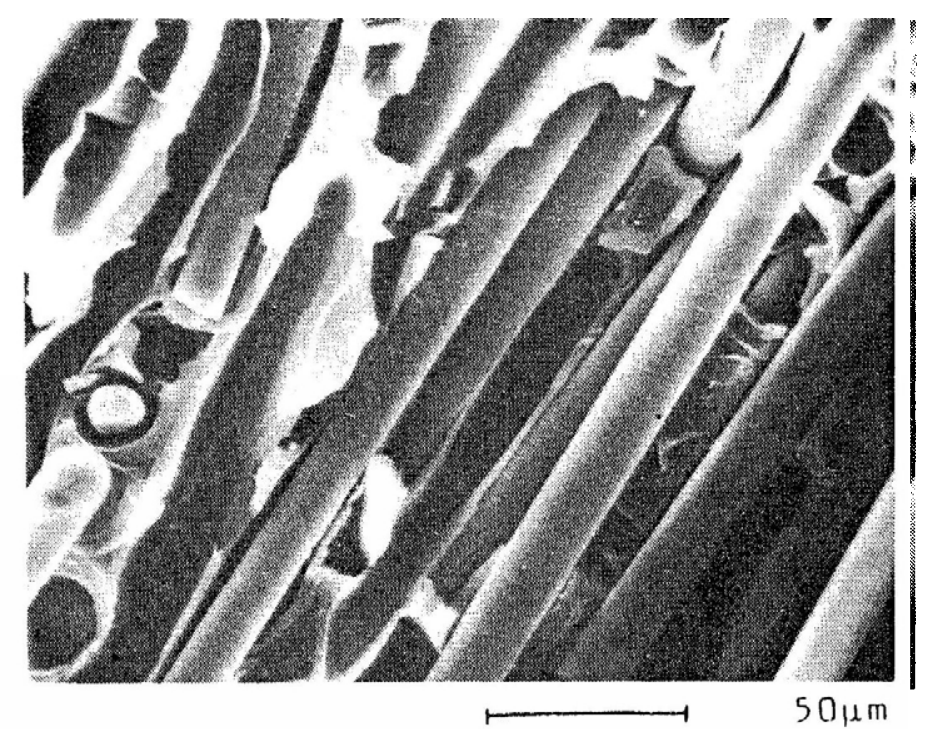

Figure 8a. Fracture surfaces of impacted POM-samples as a function of crack direction and matrix toughness: fracture parallel to the fibers (major portion on L-cracks samples) of POM I with $25 \%$ GF.

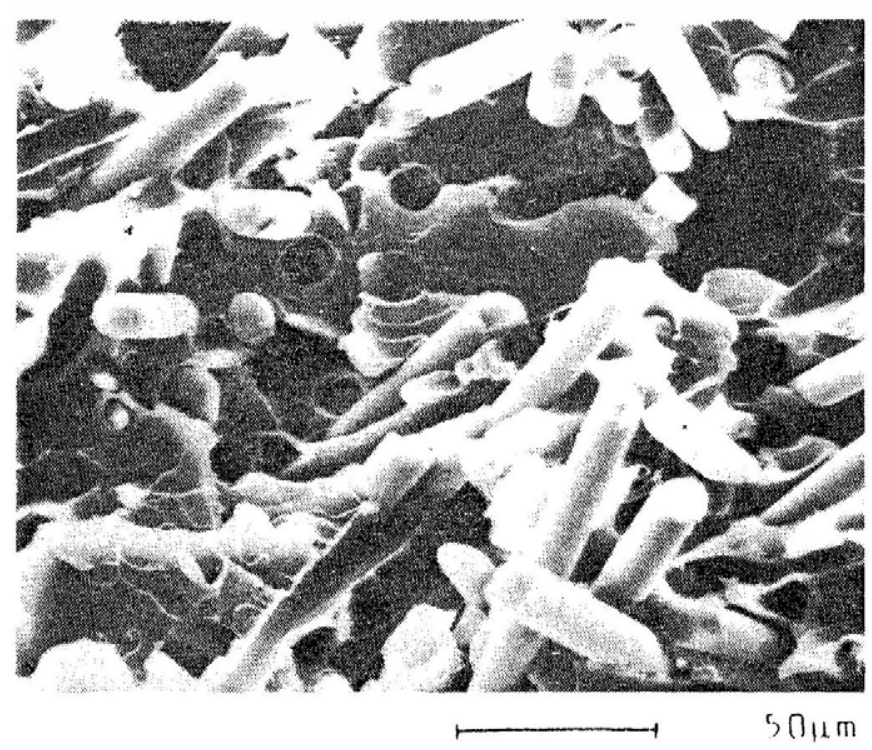

Figure 8b. Fracture surfaces of impacted POM-samples as a function of crack direction and matrix toughness: fracture perpendicular to the fibers (major portion on T-cracks samples) of POM I with 25\% GF. 


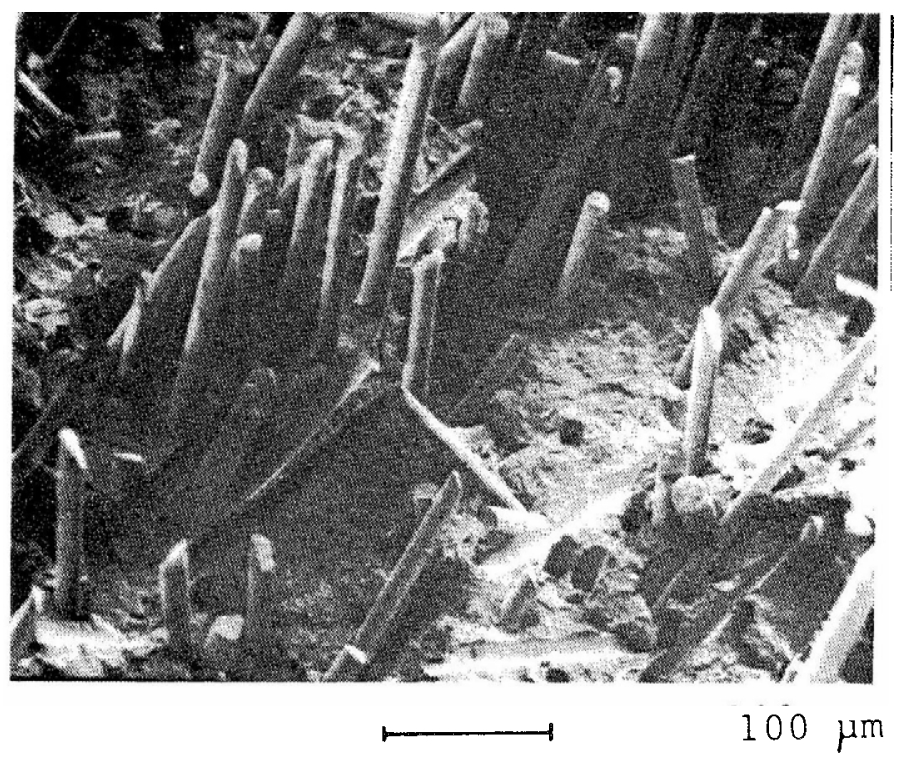

Figure 8c. Fracture surfaces of impacted POM-samples as a function of crack direction and matrix toughness: as b) for POM lla with $25 \%$ GF.

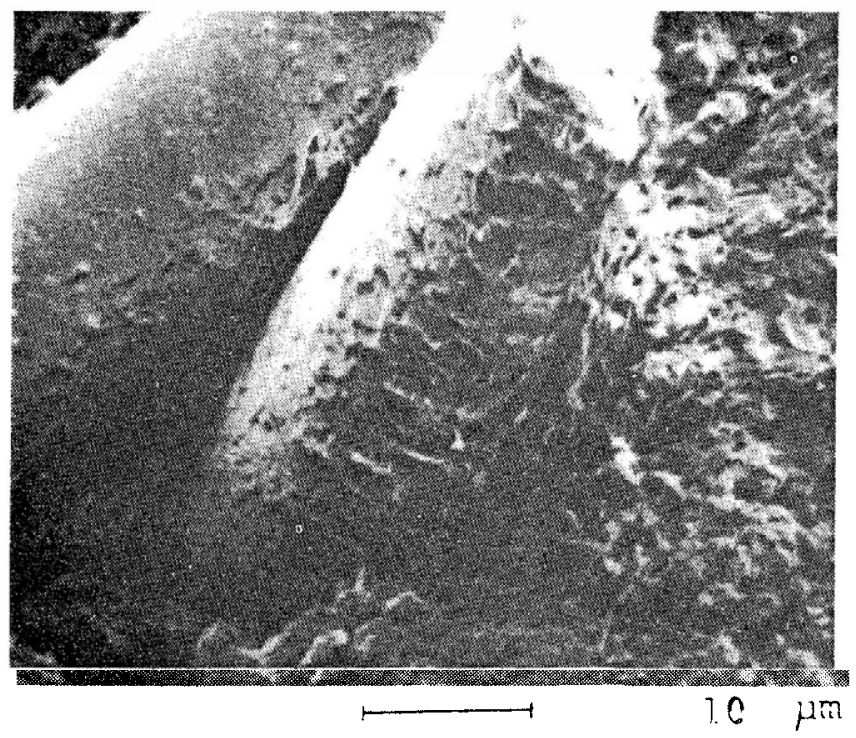

Figure 8d. Fracture surfaces of impacted POM-samples as a function of crack direction and matrix toughness: higher magnification of $\mathrm{C}$ ), showing good adhesion of matrix material to the glass fibers. 


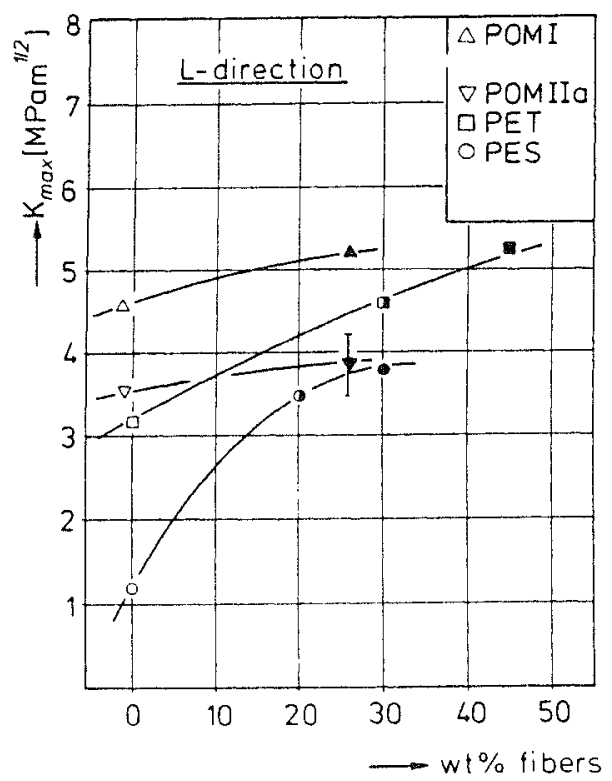

Figure 9a. Fracture toughness as calculated from the maximum of the load-displacement curves $\left(K_{\max }=K_{c}\right)$, achieved with compact tension specimens: with cracks in L-direction.

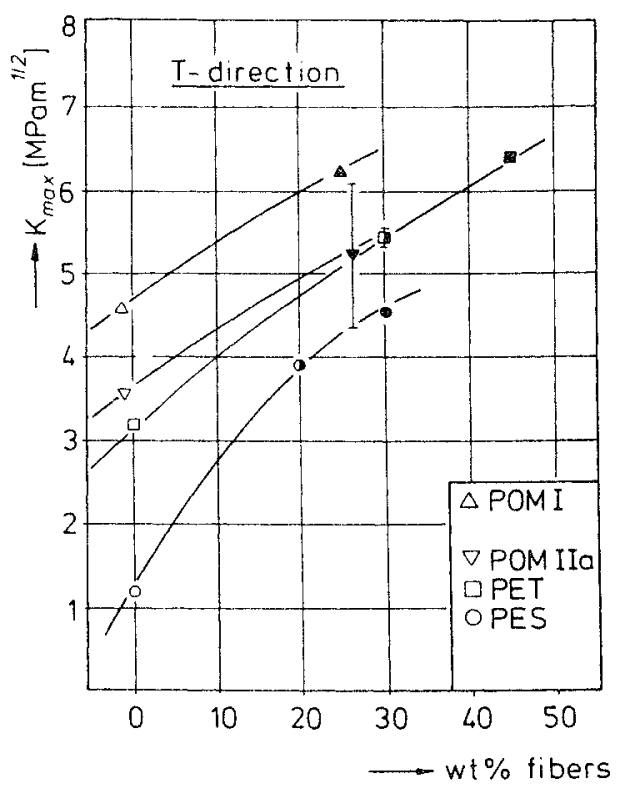

Figure 9b. Fracture toughness as calculated from the maximum of the load-displacement curves $\left(K_{\max }=K_{c}\right)$, achieved with compact tension specimens: with cracks in T-direction. 

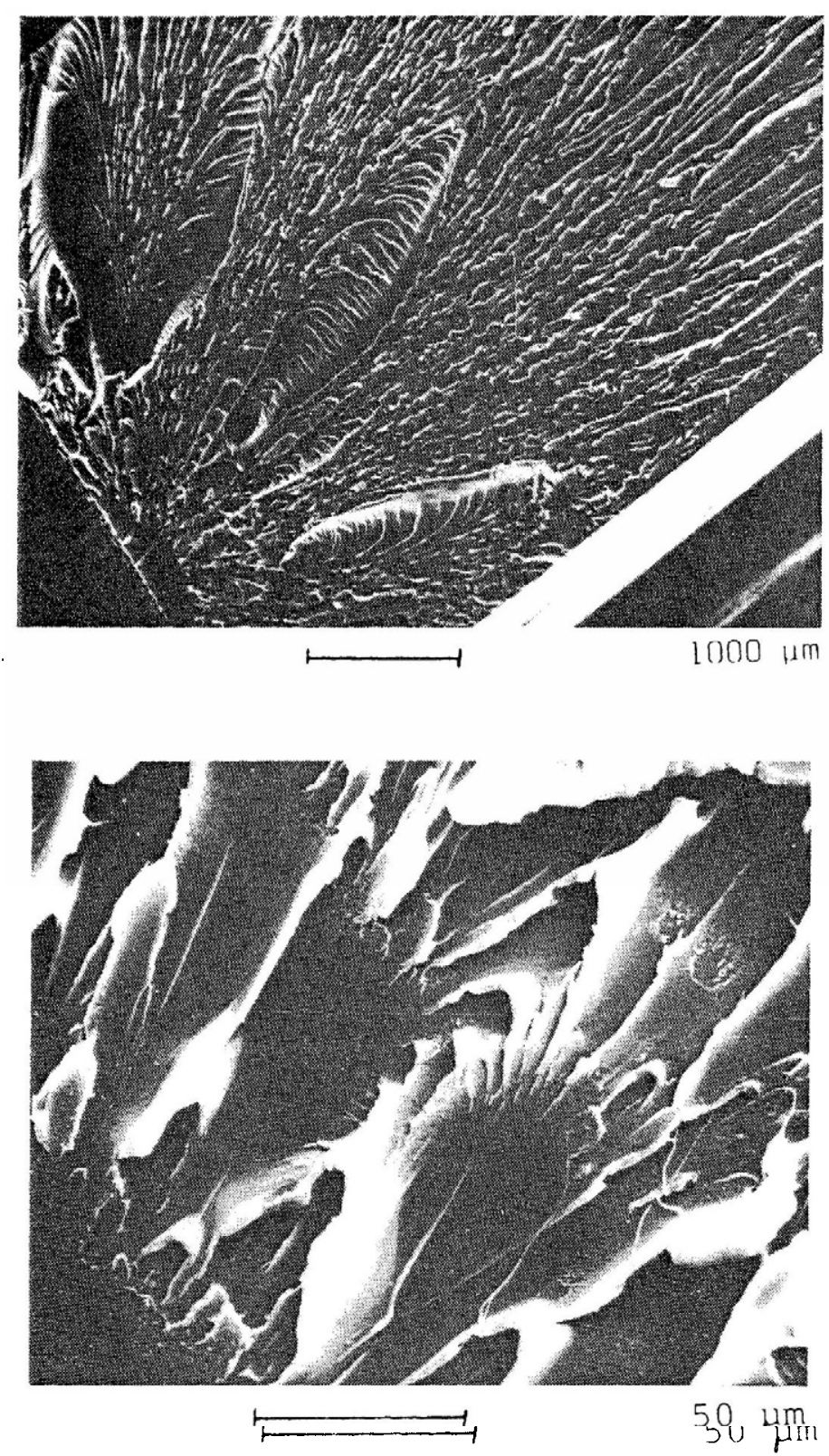

Figure 10. The fracture surface of the unfilled PES shows a very brittle failure behaviour in the notched fracture mechanics test. 


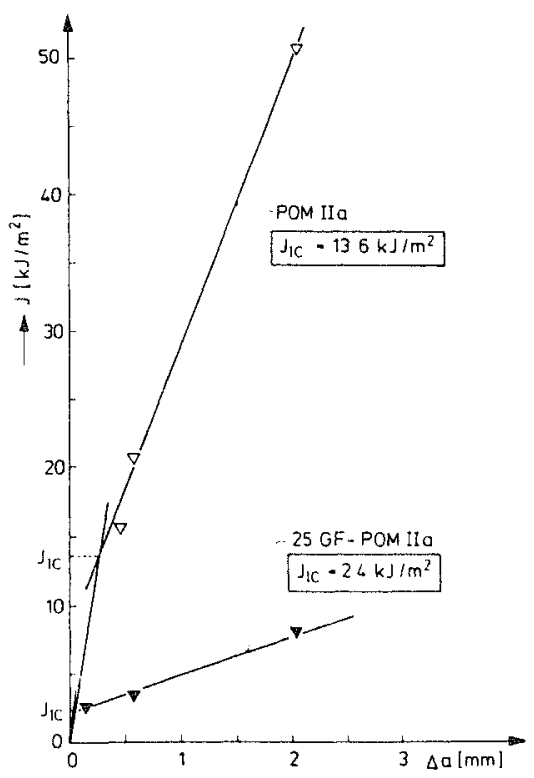

Figure 11a. Determination of the $J_{1 c}$ value: toughened and fiber reinforced POM $/ 1$.

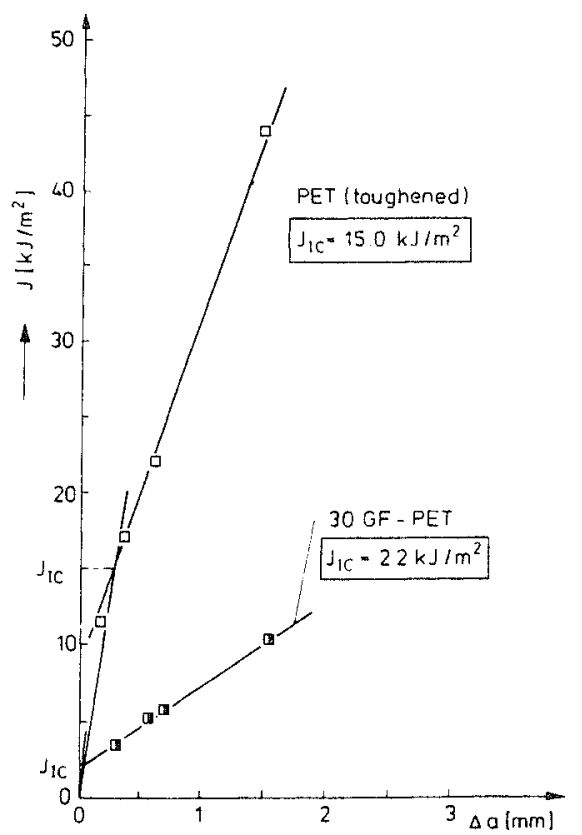

Figure 11b. Determination of the $J_{i c}$ value: toughened and fiber reinforced PET. 84 
Table 3. Fracture energy data $\left(G_{c \max }=G_{c}\right)$ as calculated from both the

$K_{\mathrm{c}}$-data measured and the elastic moduli taken from the companies'

product descriptions. In some cases, measured $J_{l c}$-values as listed for comparison with the $\mathrm{G}_{\mathrm{c}}$-data.

\begin{tabular}{|c|c|c|c|c|}
\hline Material & $K_{c_{\text {max }}^{*}}^{*}[\mathrm{MPa} \sqrt{m}]$ & E† [MPa] & $\mathrm{G}_{c_{\max }^{*}}^{*}\left[\mathrm{~kJ} / \mathrm{m}^{2}\right]$ & $\mathrm{J}_{\mathrm{ic}}^{*}\left[\mathrm{~kJ} / \mathrm{m}^{2}\right]$ \\
\hline POM-I & 4.6 & 3088 & 6.85 & - \\
\hline 25GF-POMI & 5.8 & 8074 & 4.16 & - \\
\hline POM-lla & 3.6 & 917 & 14.13 & 13.6 \\
\hline 25GF-POM $\| \mathrm{la}$ & 4.6 & 4274 & 4.95 & 2.4 \\
\hline PET & 5.2 & 1769 & 15.20 & 15.0 \\
\hline 30GF-PET & 5.0 & 7600 & 3.20 & 2.2 \\
\hline 45GF-PET & 5.8 & 11208 & 3.00 & - \\
\hline PES & 1.2 & 2900 & 0.96 & - \\
\hline 20GF-PES & 3.7 & 8000 & 1.71 & - \\
\hline 30GF-PES & 4.2 & 10500 & 1.68 & - \\
\hline
\end{tabular}

"As calculated by $G_{c}=K_{c}^{2} / E$.

- As measured.

†From literature.

6a,b) leads to the conclusions that PES is a highly notch sensitive thermoplastic. Although it was possible to calculate for each of these materials $K_{c}$ data from the maximum loads and the initial crack length not in all of the cases the cracks propagated in an unstable manner. This was especially pronounced in case of the particle toughened POM-II-a and the modified PET matrix. Therefore, their $K_{c}$ data must be considered as $K_{Q}$ values [4]. Especially in these cases it was worth to apply a J-integral approach, the results of which are shown on Figure 11. Both matrices absorb a much higher amount of energy necessary for stable crack growth than their fiber reinforced composites. A comparison of the $J_{I c}$ values with fracture energy values, $G_{I c}$, as calculated from the $K_{c}$ data and the elastic modulus of these materials (Table 3) results in a rather good agreement in case of the matrices, but not for the composites. The reason for this may be based on the fact that the elastic moduli taken from the literature are not quite correct for some of these samples.

\section{DISCUSSIONS}

\subsection{Comparison of the Different Materials on the Basis of Different Toughness Definitions}

From the measured characteristics in the CEAST-instrumented impact tests $\left(F_{\max }, E_{\text {lot }}\right)$ different material properties can be calculated when taking into account the different specimen geometries. In case of the MFW test the maximum load can be transferred into a shear stress necessary to punch a hole of a diameter equal to that of the striker through the plate thickness. For reasons of comparison the absolute energy value measured has to be converted into a fracture energy 
Table 4. Calculated $G_{d}$ and $K_{d}$-data from the energy to peak $\left(E_{\text {max }}\right)$ and geometrical variables of the different materials.

\begin{tabular}{|c|c|c|c|c|c|c|c|}
\hline Material & $E_{\max }[J]$ & $A_{0}\left[10^{-3} \mathrm{~m}^{2}\right]$ & $\begin{array}{c}W_{\max } \\
{\left[k J / m^{2}\right]}\end{array}$ & B[mm] & $\begin{array}{c}\overline{\mathrm{G}_{\mathrm{d}}} \\
{\left[\mathrm{kJ} / \mathrm{m}^{2}\right]}\end{array}$ & E[MPa] & $\bar{K}_{\mathrm{d}}[\mathrm{MPa} \sqrt{\mathrm{m}}]$ \\
\hline POM I & 0.055 & 0.207 & 0.266 & 3.3 & 2.12 & 3088 & 2.56 \\
\hline 25GF-POM I & 0.106 & 0.207 & 0.512 & 3.3 & 4.08 & 8074 & 5.74 \\
\hline POM lla & 0.727 & 0.207 & 3.512 & 3.3 & 27.97 & 917 & 5.06 \\
\hline 25GF.POM IIa & 0.135 & 0.200 & 0.675 & 3.17 & 5.20 & 4274 & 4.71 \\
\hline PET & 0.202 & 0.200 & 1.010 & 3.17 & 8.09 & 1769 & 3.78 \\
\hline 30GF-PET & 0.153 & 0.188 & 0.814 & 3.0 & 6.48 & 7600 & 7.02 \\
\hline 45GF-PET & 0.235 & 0.188 & 1.250 & 3.0 & 9.95 & 11208 & 10.56 \\
\hline PES & 0.113 & 0.251 & 0.450 & 4.0 & 3.59 & 2900 & 3.23 \\
\hline 20GF-PES & 0.178 & 0.251 & 0.709 & 4.0 & 5.65 & 8000 & 6.72 \\
\hline 30GF-PES & 0.087 & 0.251 & 0.347 & 4.0 & 2.76 & 10500 & 5.38 \\
\hline
\end{tabular}

$W_{\text {tot }}$ (unit: $\mathrm{KJ} / \mathrm{m}^{2}$ ). Concerning the NII data it is possible to calculate from the energy to peak and the initial crack length a dynamic fracture energy value, $\bar{G}_{d}$, using the geometrical correction function described by Plati and Williams for the Izod specimen [5]. The absolute value of the dynamic fracture toughness, $\bar{K}_{d}$, was derived from $\bar{G}_{d}$ by using the well known relationship between both quanti-

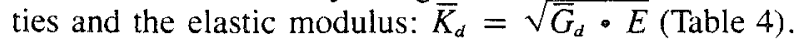

Table 5 summarizes all the maximum load (stress) related toughness values obtained with the different polymers and composites. In each column besides the actual value of either $\tau_{\text {max }}, K_{I d}$, or $K_{I c}$ a ranking order for the different materials based on the actual value in this column is given. It is obvious that the order of the individual ranks is very different in the individual columns, therefore it seems that there is no direct correlation between the mechanical properties calculated here. For example PES with the highest rank in the modular falling weight category shows very poor ranking positions in the two other categories where notched samples were used for the testing (i.e. PES must be a very notchsensitive polymer). For simplification a weight factor of 1 was used for averaging the ranks of each material in the three different columns in order to come up with an average rank for the strength-related toughness profile. This competition was won by the material $45 \mathrm{wt} \%$ GF-PET, followed by materials $30 \mathrm{wt} \%$ GF-PET and the 25 wt \% GF-POM I system.

In the same way the materials can be compared with respect to their energy related toughness properties. In this case the winner of the MFW test series was again PES, but also the toughened POM and PET matrices turned out to be of quite a high quality. Again the figures totally change if sharp notches are involved in the determination of the toughness properties of PES. Here the values of PES fall far below the average. Position No. 1 in the ranking order of the average of the energy related toughness values was achieved by material POM IIa (particle toughened POM). The second place was occupied by the toughened, but unrein- 


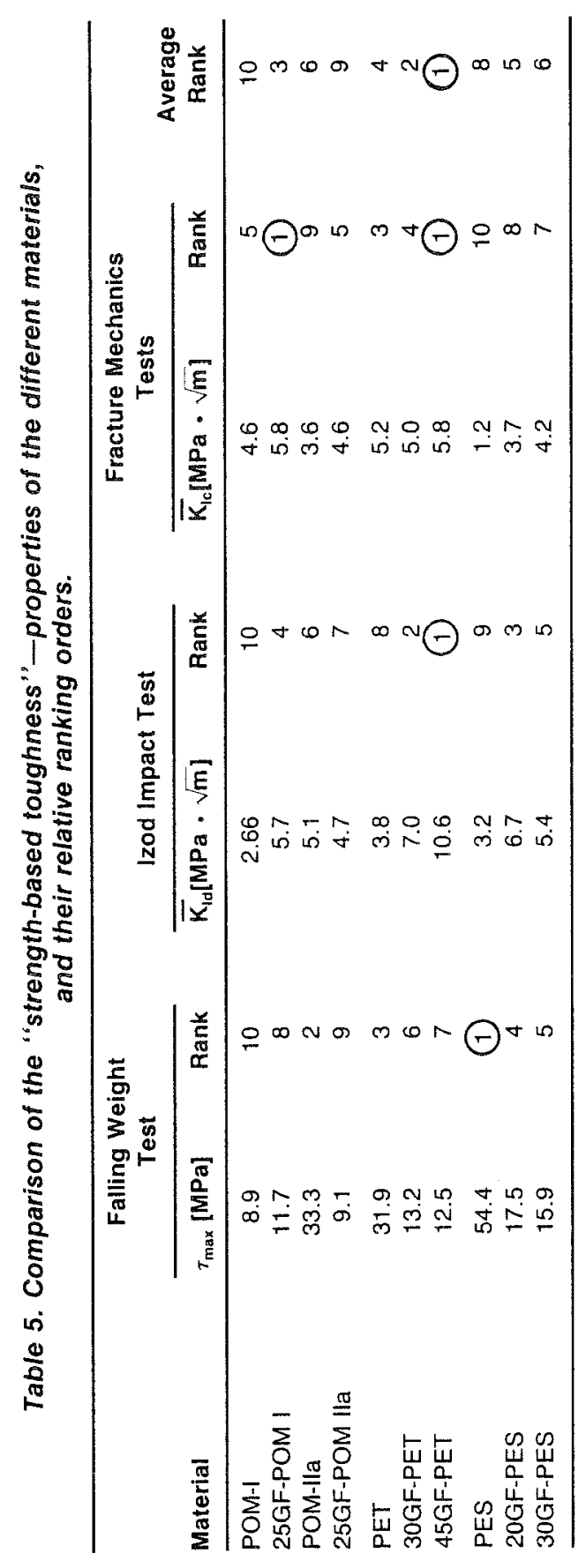




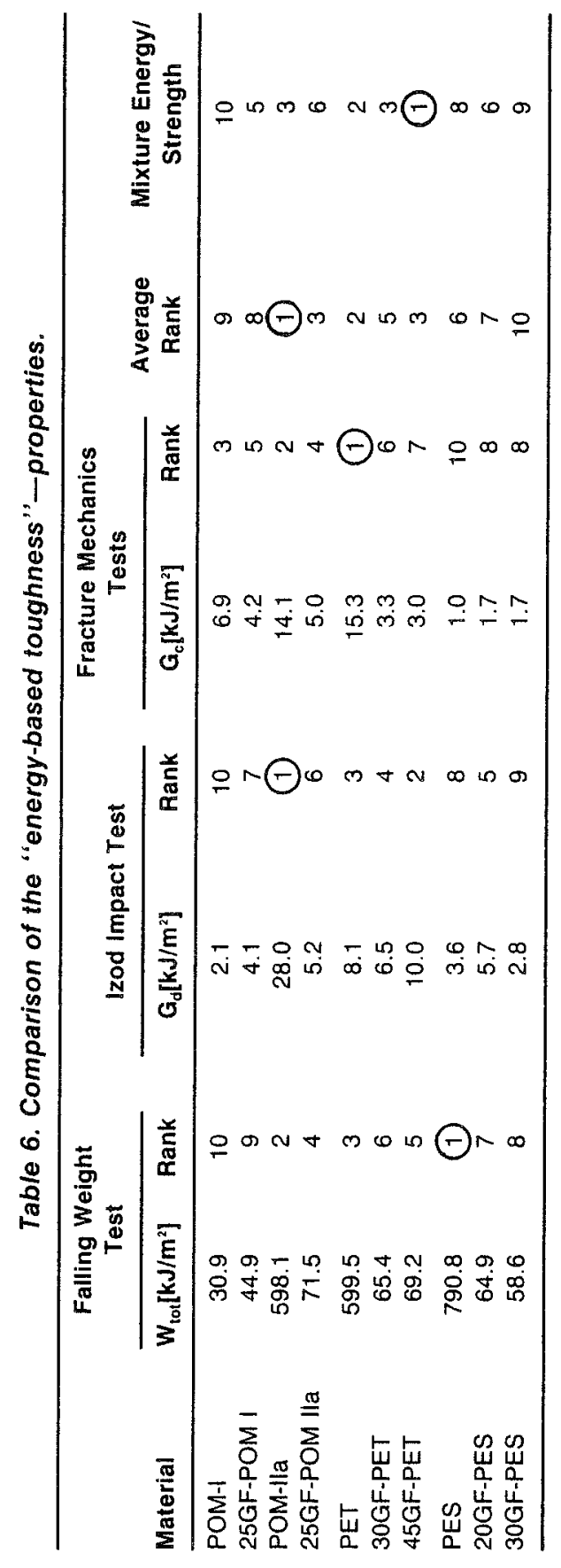


forced PET system, and both 25 wt\% GF-POM IIa and 45 wt\% GF-PET came in position No. 3 (Table 6).

The last column in Table 6 gives an idea for the materials with an overall favourable toughness performance. As expected, $45 \mathrm{wt} \%$ GF-PET, a combination of toughening particles and reinforcing fibers in a PET-matrix proved best. Next to this top position, the particle toughened PET and POM Пa matrices were found.

\subsection{Relationships between Different Toughness Data}

In an analogy to similar studies performed by experimenters from General Motors [6,7], it was attempted to find any correlations between the differently defined toughness data obtained under the different testing conditions. From the numerous possibilities of data correlation only those were selected in which the data to be compared had at least something in common, for example the same or a similar stress state, sample with a razor notch, toughness value either related to strength or more related to energy.

In order to work with dimensionless quantities, the measured characteristics in each column of Table 5 and 6 were first normalized to their average value (Table 7).

However, in spite of the restrictions mentioned it was almost impossible to find any reliable correlations between the different toughness data when plotting them against each other for all the materials in one diagram. Some typical examples are shown in Figure 12 a-d. Even additional restrictions, now with respect to different material groups (e.g. plotting only the data of the short fiber composites)

Table 7. Matrix of the normalized measured characteristics (energy-and strength-based "toughness" data) of the different materials tested.

\begin{tabular}{|c|c|c|c|c|c|c|}
\hline \multirow[b]{2}{*}{ Material } & \multicolumn{3}{|c|}{ lzod } & \multicolumn{3}{|c|}{ F.M. } \\
\hline & $\begin{array}{c}\text { M.F.W. } \\
\text { Total } \\
\text { Energy }\end{array}$ & $\begin{array}{l}\text { Izod } \\
\text { Fracture } \\
\text { Energy }\end{array}$ & $\begin{array}{c}\text { F.M. } \\
\text { Fracture } \\
\text { Energy }\end{array}$ & $\begin{array}{l}\text { M.F.W. } \\
\text { Shear } \\
\text { Strength }\end{array}$ & $\begin{array}{c}\text { Dynamic } \\
\text { Fracture } \\
\text { Toughness }\end{array}$ & $\begin{array}{c}\text { Static } \\
\text { Fracture } \\
\text { Toughness }\end{array}$ \\
\hline POM-I & 0.13 & 0.28 & 1.23 & 0.43 & 0.47 & 1.05 \\
\hline 25 GF-POMI & 0.19 & 0.54 & 0.75 & 0.56 & 1.04 & 1.33 \\
\hline POM-Ila & 2.54 & 3.68 & 2.51 & 1.60 & 0.93 & 0.82 \\
\hline 25 GF-POM $\| l a$ & 0.30 & 0.68 & 0.89 & 0.44 & 0.86 & 1.05 \\
\hline PET & 2.38 & 1.06 & 2.72 & 1.53 & 0.69 & 1.19 \\
\hline 30GF-PET & 0.28 & 0.85 & 0.59 & 0.63 & 1.28 & 1.14 \\
\hline 45GF-PET & 0.29 & 1.31 & 0.53 & 0.60 & 1.93 & 1.33 \\
\hline PES & 3.36 & 0.47 & 0.18 & 2.62 & 0.58 & 0.28 \\
\hline 20GF-PES & 0.28 & 0.75 & 0.30 & 0.84 & 1.22 & 0.85 \\
\hline 30GF-PES & 0.25 & 0.37 & 0.30 & 0.76 & 0.99 & 0.96 \\
\hline
\end{tabular}




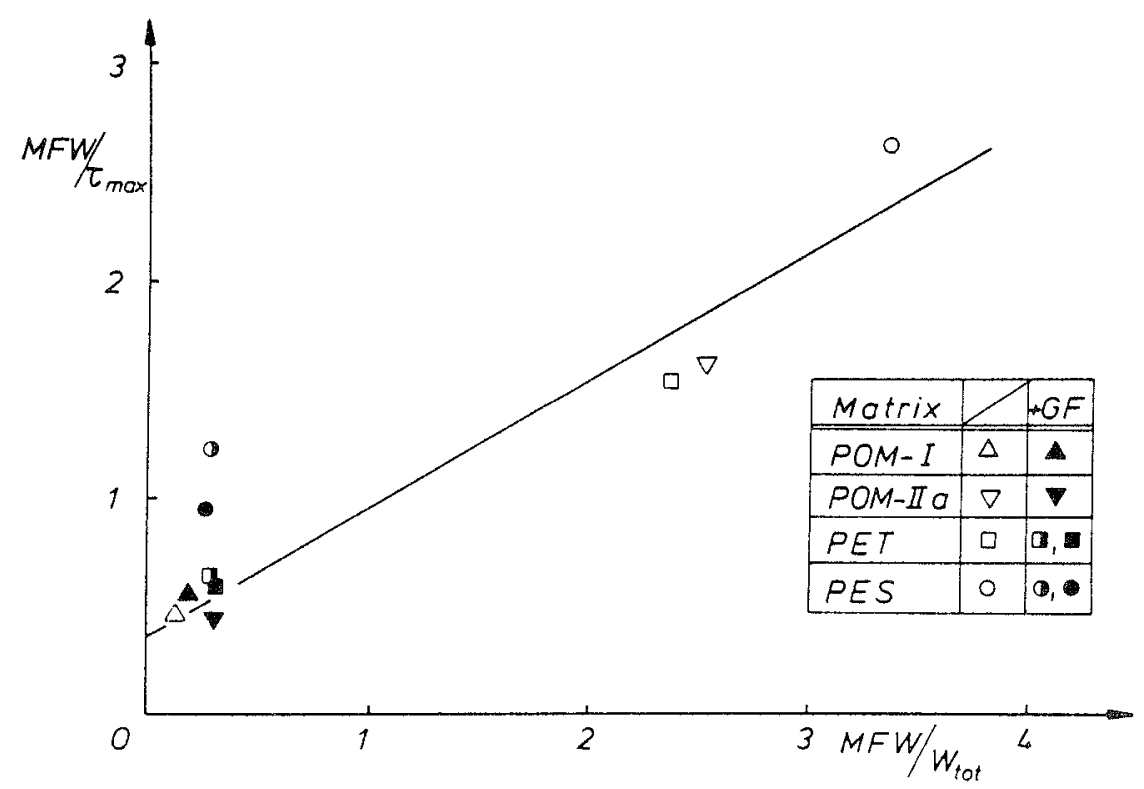

Figure 12a. Plots of different response features (obtained under the same or a different "toughness" test) against each other (different symbols refer to the different test materials,

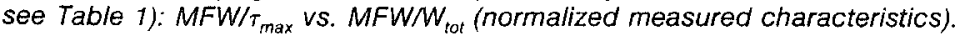

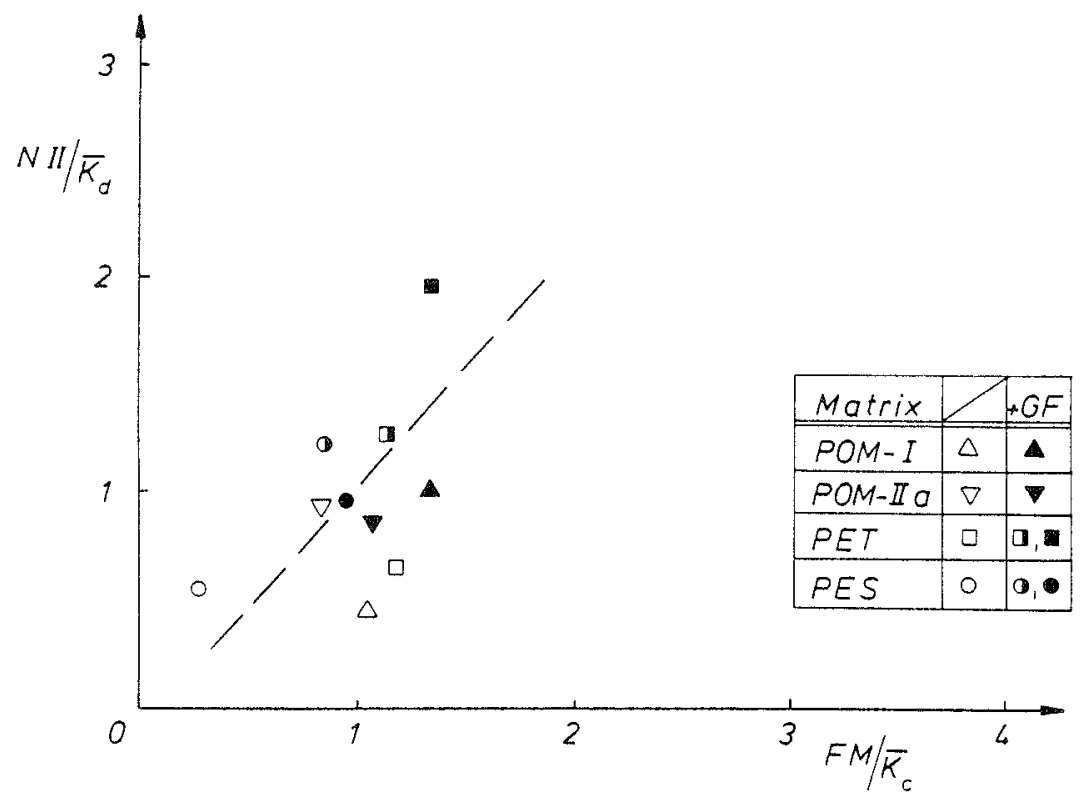

Figure 12b. Plots of different response features (obtained under the same or a different "toughness" test) against each other (different symbols refer to the different test materials, see Table 1): NII/K $K_{d}$ vs. FM/K .

90 


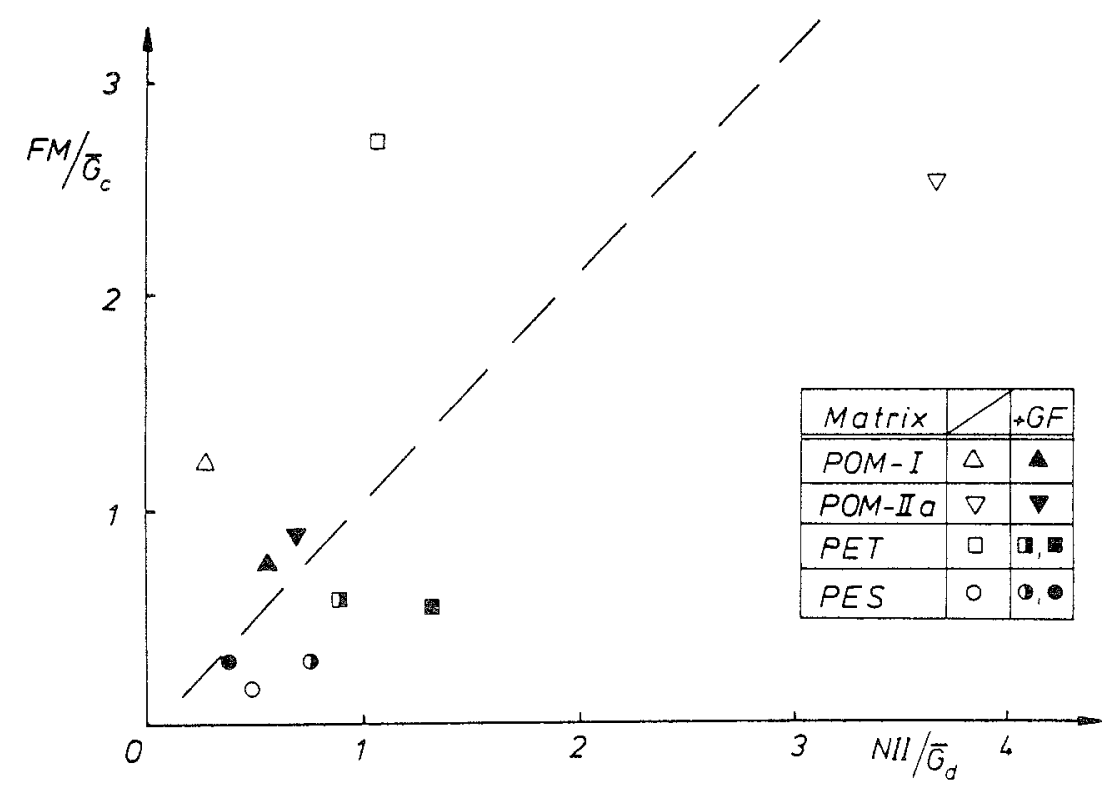

Figure 12c. Plots of different response features lobtained under the same or a different "toughness' test) against each other (different symbols refer to the different test materials, see Table 1): $F M / G_{c} v s$. $N I I / G_{d}$.

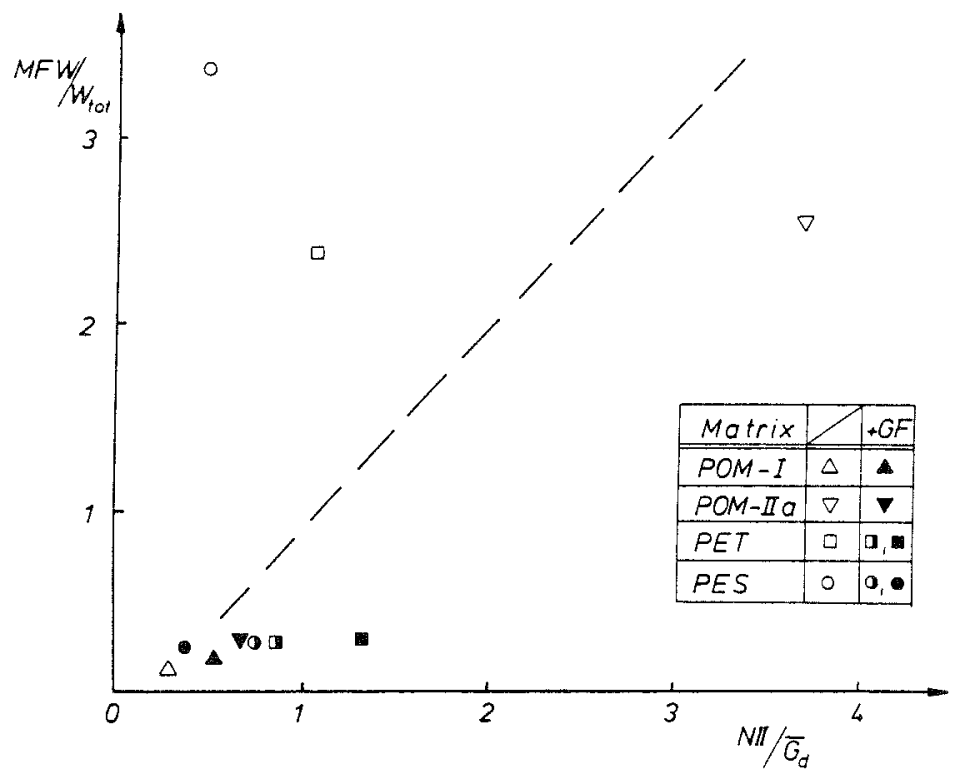

Figure 12d. Plots of different response features (obtained under the same or a different "toughness" test) against each other (different symbols refer to the different test materials, see Table 1): MFW/W tot vs. $N I I / G_{d}$. 
Table 8. Correlation coefficients ( $r$ ) between different tests and/or response features, determined by linear regression analysis.

\begin{tabular}{cllc}
\hline No. & $\begin{array}{l}\text { 1. Test and/or } \\
\text { Response Feature }\end{array}$ & $\begin{array}{l}\text { 2. Test and/or } \\
\text { Response Feature }\end{array}$ & $\begin{array}{c}\text { Correlation } \\
\text { Coefficient (r) }\end{array}$ \\
\hline 1 & $\mathrm{MFW} / \tau_{\max }$ & $\mathrm{MFW} / \mathrm{W}_{\text {tot }}$ & 0.96 \\
2 & $\mathrm{~N} I 1 / \bar{G}_{d}$ & $\mathrm{MFW} / \mathrm{W}_{\mathrm{tot}}$ & 0.43 \\
3 & $\mathrm{~N} I 1 / \bar{G}_{d}$ & $\mathrm{FM} / \mathrm{G}_{c}$ & 0.62 \\
4 & $\mathrm{~N} I 1 / K_{d}$ & $\mathrm{FM} / K_{c}$ & 0.42 \\
5 & $\mathrm{FM} / K_{c}$ & $\mathrm{FM} / G_{c}$ & 0.12 \\
\hline
\end{tabular}

did not yield any improvements. A calculation of correlation coefficients $(r)$ according to standard statistics methods [8] gave only for the comparison of the maximum load related shear strength $\tau_{\max }$ (of the MFW-test) and the total energy to failure in this test a value of $r \geq 0.8$. Below this value, the correlation between test methods must be considered as statistically insignificant (Table 8).

\section{CONCLUDING COMMENTS}

The findings of this study can be summarized in form of the following statements on the testing methods and the material qualities, respectively:

\subsection{Test Methods}

a. The toughness characteristics of a wide range of polymers and composites can be measured using several currently available test methods. Here, the notched Izod, the fracture mechanics, and the modular falling weight test were successfully applied. They lead, however, to different ranking orders between the materials tested.

b. In general, results from these different toughness tests do not correlate, even if there exist similarities of the measured characteristics and the stress states in the different tests.

c. Materials ranking and selection for performance under "toughness" requiring conditions should be made with a test method having the same loading conditions (stress state etc.) and measured characteristic which match the loading conditions, controlling variables, and failure limits of the intended application.

d. A set of more than one toughness test method is definitely required to provide a materials characterization for any reasonably complicated application.

e. Impact test must be instrumented to provide the response data necessary to characterize the complete material behavior.

f. Material "toughness" performance rankings vary between different test methods; therefore, the latter must be assigned a weightiness factor based on design priorities. 


\subsection{Materials Ranking}

a. "Toughness" measurements of different short fiber reinforced and unfilled thermoplastics were performed by a fracture mechanics test (F.M.), an Izod impact test (N.I.I.), and a modular falling weight test (M.F.W.). Ranking of the materials was performed on the basis of both, energy- and strength-based "toughness" definitions.

b. In the M.F.W. tests, highest values in both shear strength and total fracture energy (unnotched samples) were reached by the PES matrix, followed by the two other, particle toughened thermoplastics (POM-IIa, PET). The fiber reinforced systems were very low with respect to $W_{\text {to }}$, and about half of the matrix values in case of $\tau_{\text {max }}$.

c. In the Izod tests (notched samples), the thermoplastic POM-IIa matrix achieved the highest $\bar{G}_{d}$-value, whereas the strength based $\bar{K}_{d}$-value was highest for the 45 GF-PET system.

d. In the fracture mechanics tests (notched), the highest fracture energies were found for the toughened PET and POM matrizes. The strength based $\bar{K}_{c}$-value was, on the other hand, highest for the $45 \mathrm{GF}$-PET and the $25 \mathrm{wt} \%$ GF-POM systems.

e. The average of the strength based "toughness"-data (weighting factor always 1) was won by the 45 GF-PET-system, that of the energy based "toughness"data by POM-IIa, and the mixture of both was also won by the particle toughened PET-matrix, reinforced with 45 wt $\%$ glass fibers.

\section{ACKNOWLEDGEMENTS}

The authors are grateful to the following companies for providing the testing materials: a) du Pont de Nemours Inc., Wilmington, Delaware, USA (POM and PET systems); b) BASF A.G., Ludwigshafen, West Germany (PES system). One of us, K. Friedrich, greatly appreciates the financial support by the Polymer Products Dept. of E.I. du Pont de Nemours Inc., Wilmington, Delaware, USA, for buying part of the testing equipment.

\section{REFERENCES}

1. Friedrich, K. Composite Sci. Technol., 22:43 (1985).

2. Friedrich, K., R. Walter, H. Voss and J. Karger-Kocsis. Composites, 17:205 (1986).

3. Voss, H. and K. Friedrich. J. Mater. Sci. 21:2889 (1986).

4. Karger-Kocsis, J. and K. Friedrich. Polymer, 27:1756 (1986).

5. Plati, E. and J. G. Williams. Polym. Eng. Sci., 15:470 (1975).

6. Roche, J. L. and S. N. Kakarala. Proc. of ASTM-Symp. Instrumented Impact Testing of Plastics and Composite Materials, APMES 85, Houston, Texas (March 11, 1985).

7. Kakarala, S. N. and J. L. Roche. Ibid. (1985).

8. Stingl, P. Statistik, Hanser, München (1981). 